The FASEB Journal express article 10.1096/fj.03-1376fje. Published online January 7, 2005.

\title{
Engagement of CD44 modulates cyclooxygenase induction, VEGF generation, and cell proliferation in human vascular endothelial cells
}

\author{
Joseph F. Murphy, ${ }^{*}$ Frances Lennon, ${ }^{\dagger}$ Christopher Steele, ${ }^{*}$ Dermot Kelleher, ${ }^{*}$ \\ Desmond Fitzgerald, ${ }^{*}$ and Aideen Long ${ }^{\dagger}$
}

Departments of *Clinical Pharmacology and "Biochemistry, Royal College of Surgeons in Ireland, Dublin 2; and ${ }^{\star}$ Dept of Clinical Medicine, Trinity College, and Dublin Molecular Medicine Centre, St. James's Hospital, Dublin 8, Ireland

Corresponding author: Joseph F. Murphy, Department of Clinical Pharmacology, Royal College of Surgeons in Ireland, Dublin 2, Ireland. E-mail: joseph.murphy@emmerex.com

\begin{abstract}
CD44 is a receptor for hyaluronic acid and is found on the surface of hematopoetic cells and in mesenchymal tissue. It is also expressed on endothelial cells (EC). Cyclooxygenase (COX) is the rate-limiting enzyme in the production of prostaglandins in EC. Here we show that engagement of CD44 with signaling monoclonal antibodies (mAbs) or its natural ligand hyaluronic acid induces COX-2 and prostacyclin $\left(\mathrm{PGI}_{2}\right)$ formation in human EC. This induction was blocked by $\mathrm{mAbs}$ that have been shown to inhibit CD44-mediated intracellular signaling. COX-1 induction was not observed after CD44 ligation. CD44-stimulated COX-2 activation/PGI 2 production was accompanied by the production of the potent endothelial mitogen, vascular endothelial growth factor (VEGF) and was inhibited by a neutralizing VEGF antibody. Moreover, this COX-2 induction was also associated with an increase in EC proliferation that was inhibited by the blocking anti-CD44 mAbs and a COX-2-specific inhibitor. This is the first study to show that engagement of CD44 with mAbs or its natural ligand induces COX-2, generates VEGF, and thus leads to an increase in EC proliferation. Results from this study may have important and widespread implications for the development of novel therapeutic agents for modulating blood vessel growth during ischemic heart disease, during inflammation, or around solid tumors.
\end{abstract}

Key words: vascular endothelial growth factor $\bullet$ prostacyclin $\bullet$ COX

he cell adhesion molecule CD44 is involved in a variety of important biological events
such as embryogenesis, hematopoiesis, lymphocyte homing and activation, inflammatory
reactions, and tumor dissemination (1-4). CD44 represents a large protein family, which
includes the standard form or CD44 with a molecular mass of $85-90 \mathrm{kDa}$, and a multiplicity of
isoforms generated by alternative splicing of transcripts and subsequent variable glycosylation
(reviewed in ref 5). These high molecular mass variants are rarely expressed on normal cells.
CD44 is the principal cell surface receptor for extracellular matrix glycosaminoglycan
hyaluronan (HA). CD44-HA-mediated cell adhesion is important in several pathophysiological 
processes such as inflammation and metastatic spread of cancer cells. In this context, it has been recognized that CD44 can function as a signaling receptor in a variety of cell types (6). Cell stimulation by monoclonal anti-CD44 antibody or natural CD44 ligands activate signaling pathways that culminate in cell proliferation, cytokine secretion, chemokine gene expression, and cytolytic effector functions. Normal endothelial cells (EC) express low levels of CD44, but expression is up-regulated by activation with, for example, cytokines, and by culturing of these cells (7). Expression is also increased on the vasculature of solid tumors $(7,8)$. Expression of CD44 on EC is associated with homing and migration of leukocytes (i.e., inflammation and migration). In addition, it has been demonstrated that CD44 plays some role in new blood vessel formation (angiogenesis), although its precise role in this process is not clear $(7,9,10)$.

EC proliferation is driven by the growth factor vascular endothelial growth factor (VEGF) that enhances vascular permeability (11) and stimulates angiogenesis in vivo (12). Several VEGF isoforms, including $\mathrm{VEGF}_{121}, \mathrm{VEGF}_{145}, \mathrm{VEGF}_{165}, \mathrm{VEGF}_{199}$, and $\mathrm{VEGF}_{206}$, have been identified $(13,14)$, which are products of a single gene. VEGF acts through two high affinity tyrosine kinase receptors expressed by EC and hematopoietic cells, flt-1 (VEGFR-1) and KDR (VEGFR2) $(15,16)$. Moreover, Soker et al. (17) identified a novel VEGF receptor that binds to VEGF 165 but not $\mathrm{VEGF}_{121}$. Among several signals, VEGF can induce prostacyclin $\left(\mathrm{PGI}_{2}\right)$ generation by $\mathrm{EC}(18,19)$. $\mathrm{PGI}_{2}$ is a member of a family of potent biological mediators termed prostaglandins (PGs), which are implicated in the pathogenesis of cardiovascular disease, inflammation, and cancer. The formation of PGs is highly regulated at a number of points in their biosynthetic pathway. One of these is the enzyme cyclooxygenase (COX) of which there are two isoforms, COX -1 and COX-2, that are the products of distinct genes. COX-1 is constitutively expressed in most tissues and cell types (20) and is induced during cell differentiation and angiogenesis (21, 22). COX-2 is rarely detected but is induced by several stimuli, including cytokines, hormones, and growth factors $(23,24)$. Recently, we have shown that both isoforms are induced after exposure to VEGF (25). Moreover, we have demonstrated that signaling through the integrin $\alpha_{v} \beta_{3}$, which is also expressed on EC, results in $\mathrm{PGI}_{2}$ formation and COX-1 and -2 induction (26).

As CD44 expression has previously been associated with inflammatory processes, cancer metastasis, and angiogenesis, we investigated whether signaling through CD44 in EC could induce $\mathrm{PGI}_{2}$ formation, $\mathrm{COX}-2$ induction, and VEGF secretion. We found that both cross-linking CD44 using antibodies and engagement with the physiological ligand HA resulted in upregulation of COX-2 expression and $\mathrm{PGI}_{2}$ formation with no significant COX-1 induction. Signaling through CD44 also resulted in stimulation of VEGF secretion and EC proliferation. Neutralizing antibodies to VEGF significantly inhibited CD44-stimulated COX-2 induction/PGI ${ }_{2}$ formation. Furthermore, CD44-induced EC proliferation was inhibited by a COX-2-selective inhibitor. These results implicate CD44 as having a key role, not just as an adhesion molecule, but also as a signaling molecule the engagement of which results in the production of molecules central to processes such as inflammation, metastasis, and angiogenesis.

\section{MATERIALS AND METHODS}

All laboratory reagents were from Sigma Chemical Co., (St. Louis, MO) unless otherwise stated. Culture medium (M199), fetal calf serum (FBS), antibiotics, Hanks' balanced salt solution (HBSS), phosphate buffered saline (PBS), and HEPES were from Life Technologies Inc. (Paisley, UK). NS398 was from Cayman Chemical Co. (Ann Arbor, MI). SC 560 was a kind gift 
from Dr. Peter Isakson at Searle (Skokie, IL). Hylauronic acid fragments (200 kDa) were from ICN Biomedicals.

\section{Monoclonal antibodies (mAbs)}

For the anti-CD44 antibodies, D2.1 monoclonal antibody was produced by immunizing mice with HUT 78 (T cell lymphoma) cells using standard hybridoma technology (27, 28, unpublished observations). L3D1 was a kind gift from Dr. Bishr Omary (Stanford University), and Bric 238 was from Dr. P. A. Judson (Bristol, UK) (29); KM201 was a kind gift from Dr. Katherine Fitzgerald (Trinity College, Dublin), and IM7.8.1 and Anti-IE (HB 179) were from the American Type Culture Collection (ATCC).

\section{Culture of human umbilical vein endothelial cells (HUVEC)}

EC were isolated and grown in culture as described by Jaffe et al. (30). Briefly, cells were isolated from human umbilical vein cords by enzymatic digestion using collagenase type II (Worthington Chemical Co., Freehold, NJ) and grown in medium 199 supplemented with 10$20 \%$ FBS and penicillin/streptomycin (100 U). EC mitogen (Biogenesis, Poole, England) was solubilized with heparin (1000 U) and added at a final concentration of $100 \mu \mathrm{g} / \mathrm{ml}$. Cells were grown to confluence on gelatin-coated $75 \mathrm{~cm}^{2}$ flasks (COSTAR, Cambridge, MA) in a humidified atmosphere at $37^{\circ} \mathrm{C}$ in $5 \% \mathrm{CO}_{2}$. Confluent primary cultures were routinely passaged by trypsin/EDTA digestion and expanded through passages 2-3.

\section{Detection of CD44 on HUVEC}

CD44 expression on HUVEC was determined by Western blot analysis. Cells were isolated and cultured as described above. Detergent-soluble lysates were prepared by incubating the cells in a TBS containing 1\% Triton X-100, $1 \mathrm{mM}$ EDTA, and protease inhibitors, and the lysates were separated by $10 \%$ PAGE. Resolved proteins were transferred to a PVDF membrane (for $1 \mathrm{~h}$ using a semidry system), which was blocked using notfat dried milk (in PBS) and then probed with an anti-CD44 specific antibody (Bric 238) followed by a secondary HRP-labeled, secondary rabbit anti-mouse antibody. Blots were stripped by incubating them in $100 \mathrm{mM} \beta$ mercaptoethanol, $2 \% \mathrm{SDS}, 62.5 \mathrm{mM}$ Tris-HCl, $\mathrm{pH} 6.7$ for $30 \mathrm{~min}$ at $60^{\circ} \mathrm{C}$, and were reprobed with an anti-actin antibody (Polyclonal from Sigma) as a loading control. Immunoreactive bands were visualized by enhanced chemical luminescence (ECL) and autoradiography.

\section{Estimation of COX isozyme induction}

EC to be assayed for induction of COX isoforms 1 and 2 were grown to confluence on either 6or 24-well plates and serum starved in $2.5 \%$ FBS the night before. Cells were then treated with aspirin at a final concentration of $200 \mu \mathrm{M}$ for $45 \mathrm{~min}$ to destroy all COX activity and washed twice with $50 \mathrm{ml}$ warm PBS. In experiments where a neutralizing antibody to VEGF was used, anti-VEGF $(0.1 \mu \mathrm{g} / \mathrm{ml}$; R\&D Systems, Minneapolis, MN) was added $30 \mathrm{~min}$ before addition of stimulus. Cells were then incubated in M199/2.5\% FBS alone or in medium containing phorbol myristate acetate (PMA; $1 \mu \mathrm{M})$, VEGF $(50 \mathrm{ng} / \mathrm{ml}), \mathrm{mAbs}(5-10 \mu \mathrm{g} / \mathrm{ml})$, HA, or HA fragments $(100 \mu \mathrm{g} / \mathrm{ml})$ for 3-6 h. The cells were again washed twice in PBS and treated with arachidonic acid $(150 \mu \mathrm{M})$ in $\mathrm{HBSS} / \mathrm{CaCl}$ for $10 \mathrm{~min}$. The supernatant was analyzed for 6-keto $\mathrm{PGF}_{1 \alpha}$ by 
ELISA (Assay Designs Inc., Ann Arbour, MI). The cell pellets were lysed (1\% Triton X-100 in PBS, $1 \mathrm{mM}$ EDTA, and protease inhibitors, Complete ${ }^{\mathrm{TM}}$, Boehringer-Mannheim) for $30 \mathrm{~min}$ on ice before electrophoresis and Western blot analysis. Lysate samples (20-40 $\mu \mathrm{g} / \mathrm{lane})$ were applied to a $7.5 \%$ SDS polyacrylamide minigel, electrophoresed for $2 \mathrm{~h}$ and then transferred to nitrocellulose membranes overnight at $30 \mathrm{~V}$ constant voltage at $4^{\circ} \mathrm{C}$. Nitrocellulose was checked for the presence of protein using Ponceau staining $\left(0.1 \% \mathrm{w} / \mathrm{v}, 0.1 \%\right.$ acetic acid $\mathrm{v} / \mathrm{v}$ in $\left.\mathrm{dH}_{2} \mathrm{O}\right)$, washed three times in NT buffer $(170 \mathrm{mM} \mathrm{NaCl}, 0.2 \%$ igepal detergent CA- $630 \mathrm{v} / \mathrm{v}, 50 \mathrm{mM}$ Tris, $\mathrm{pH}$ 7.4) containing 5\% bovine serum albumin (BSA), and blocked for a further $30 \mathrm{~min}$. Immunostaining for COX-1 and -2 expression was performed with either a mouse anti-human COX-1 or COX-2 monoclonal antibody (Caymen Co.). Immunoreactive bands were detected as described above.

\section{VEGF detection and cell proliferation assays}

After COX induction experiments described above, supernatant $(100 \mu \mathrm{l})$ was removed and assayed for VEGF using a Quantikine human immunoassay (R\&D Systems). The assay uses a standard recombinant human $\mathrm{VEGF}_{165}$ and recognizes native human VEGF and $\mathrm{VEGF}_{121}$. The ELISA was performed according to the manufacturer's instructions. For cell proliferation, EC were grown to 50-60\% confluence in 96-well tissue culture plates (COSTAR). mAbs, ligands, or control agents were added and incubated at $37^{\circ} \mathrm{C}$ for $8-9 \mathrm{~h}$ followed by addition of (3-[4, 5dimethylthiazol-2-y]-2, 5-diphenyltetrazolium bromide (MTT; R\&D Systems) for a further $1 \mathrm{~h}$. MTT is reduced by viable, metabolically active cells to insoluble purple formazan dye crystals. Detergent was added to the wells solubilizing the crystals, and the absorbance was read by a spectrophotometer at $570 \mathrm{~nm}$. The rate of tetrazolium reduction is directly proportional to the rate of cell proliferation. In assays where the COX-1 (SC 560, $1 \mu \mathrm{M})$ - and COX-2 (NS398, 1 $\mu \mathrm{M}$ )-specific inhibitors were used, inhibitors were added $30 \mathrm{~min}$ before addition of CD44 mAbs or ligands.

\section{Statistics}

Each experiment was carried out in replicate as described, and the data are means \pm SE for the indicated number of experiments. Statistical analysis was carried out using the Student's $t$-test.

\section{RESULTS}

\section{HUVEC express CD44}

We investigated the status of CD44 expression on cultured HUVEC. Cells were seeded at a low density $\left[1.5 \times 10^{5}\right.$ cells per flask (T75)], and CD44 expression was determined by Western blot analysis 24,48 , and $72 \mathrm{~h}$ later. It was found that levels of this molecule increased as the confluency of cells increased (Fig. 1).

\section{Anti-CD44 mAbs induce COX-2 in EC}

As CD44 is expressed on the surface of EC, we investigated whether engagement with antiCD44 mAbs would regulate COX activity and induction. mAbs or control agents were added to $\mathrm{EC}$ for 3-4 $\mathrm{h}$ and assayed for 6-keto- $\mathrm{PGF}_{1 \alpha}$ generation and COX protein expression by ELISA 
and Western blot analysis, respectively. PMA was used as positive control, as we have previously shown it to induce COX-2 and 6-keto-PGF ${ }_{1 \alpha}$ formation (25). Figure $2 \mathrm{~A}$ shows that anti-CD44 mAbs L3D1 and D2.1 significantly up-regulated the amount of 6-keto-PGF $1 \alpha$ generated by these cells. COX-2 protein expression was also induced by both mAbs (Fig. $2 B)$. A nonsignaling IgM anti-CD44 antibody, Bric238, did not affect either 6-keto-PGF ${ }_{1 \alpha}$ generation or COX-2 protein expression. COX-1 is constitutively expressed in HUVEC (Fig. 2B $)$, and none of the CD44 mAbs induced COX-1 above basal levels.

\section{Native, high molecular mass HA induces COX-2 in EC}

Having observed that the two CD44-specific signaling mAbs induced COX-2 expression in EC, we then investigated whether $\mathrm{HA}$, the natural ligand for CD44, could stimulate COX-2 induction. HA induced 6-keto- $\mathrm{PGF}_{1 \alpha}$ in a concentration-dependent manner (Fig. 2C). As there was no increase in 6-keto generation above $100 \mu \mathrm{g} / \mathrm{ml}$, this was the concentration used in all subsequent experiments. HA-stimulated 6-keto-PGF $1 \alpha$ generation was inhibited by CD44 antibodies IM7.8.1 and KM201 (ig. 2D). These antibodies have previously been shown to block HA signaling through CD44 $(31,32)$. IM7.8.1 stimulates shedding of CD44 while KM201 blocks HA binding (32). 6-keto-PGF $1 \alpha$ generation in response to HA was completely inhibited by the COX-2 inhibitor NS398 confirming that HA-driven $\mathrm{PGI}_{2}$ formation is via COX-2 (data not shown). HA also stimulated COX-2 protein expression as demonstrated by Western blot analysis (Fig. 2E). Fragments of HA, previously shown to have signaling capacity $(31,33)$, did not significantly induce 6-keto-PGF ${ }_{1 \alpha}$ formation at $100 \mu \mathrm{g} / \mathrm{ml}$ (Fig. 2D). 6-keto-PGF $1 \alpha$ was not detected at any other HA fragment concentration $(50-200 \mu \mathrm{g} / \mathrm{ml})$ tested (data not shown). Treatment of cells with PMA or ligation of CD44 with native HA or HA fragments for 3 or $6 \mathrm{~h}$ did not induce COX-1 above resting levels.

\section{CD44 engagement induces VEGF}

As COX and its by-products have been shown to be involved in EC proliferation and to regulate angiogenesis $(34,35)$, we next sought to determine whether ligand-mediated signaling through CD44 would affect generation of VEGF. VEGF is produced under hypoxic conditions but is also released during angiogenic blood vessel growth (36). VEGF was not detected in supernatant from resting cells whereas ligation of CD44 with L3D1 or D2.1 antibodies leads to a significant increase in VEGF generation (Fig. 3A). PMA was used as positive control. The nonsignaling (IgM) Bric 238 or the IgG isotype control anti-IE did not affect VEGF generation. HA also lead to a very significant increase in VEGF production that was completely inhibited by the two blocking mAbs IM7.8.1 and KM201 (ig. 3B). HA fragments did not stimulate significant VEGF production by EC (Fig. 3B).

\section{CD44-mediated 6-keto-PGF ${ }_{1 \alpha}$ generation is dependent on VEGF}

To determine whether 6-keto- $\mathrm{PGF}_{1 \alpha}$ production was dependent on the generation of VEGF, we carried out experiments similar to those above in the presence of neutralizing anti-VEGF antibody. Results show that CD44-induced 6-keto-PGF ${ }_{1 \alpha}$ by both the anti-CD44 mAb D2.1 and HA was significantly inhibited in the presence of this antibody (ig. $4 A$ and $\underline{B}$ ). These results 
indicate that CD44 mediated COX-2 induction and 6-keto- $\mathrm{PGF}_{1 \alpha}$ generation is dependent on VEGF.

\section{CD44 engagement leads to EC proliferation}

Based on these findings, we then looked at the effect of CD44 ligation on EC proliferation. EC were incubated with mAbs for a period of $8-9 \mathrm{~h}$ and then assayed for induction of cell proliferation as described in Materials and Methods. Again, both mAbs D2.1 and L3D1 significantly up-regulated EC proliferation, whereas Bric 238 and the anti-IE mAb had no effect (Fig. 5A). HA $(100 \mu \mathrm{g} / \mathrm{ml})$ also significantly increased EC proliferation that was blocked by the blocking mAbs IM7.8.1 and KM201 (Fig. 5B). HA fragments did not have a significant effect on the rate of cellular proliferation over the 8-9 $\mathrm{h}$ period. EC proliferation stimulated by HA was significantly attenuated by the COX-2 inhibitor NS398 and not by the COX-1-selective inhibitor SC 560 (Fig. 5C). Taken together, our results strongly suggest that EC proliferation can be regulated by ligation of $\mathrm{CD} 44$, and this proliferative response is related to COX-2 induction and VEGF generation.

\section{DISCUSSION}

This study has demonstrated that signaling through the adhesion molecule CD44 on EC results in the induction of COX-2 gene expression and $\mathrm{PGI}_{2}$ production, generation of VEGF, and subsequent stimulation of EC proliferation. These biological effects are both mediated via stimulating CD44 antibodies or the natural CD44 ligand HA. Although CD44 has been well characterized as a molecule that mediates cellular adhesion and motility (37), its role in cellular activation is less well described. Antibodies to CD44 have been shown to be costimulatory for T cell activation and thymocyte apoptosis (38), while HA fragment induced signaling through CD44 results in the transcription of proinflammatory genes, such as chemokines, cytokines, cell adhesion molecules, and inducible NO synthase $(39,33,40)$

Our previous results demonstrating COX induction by the vitronectin receptor $\alpha_{\mathrm{v}} \beta_{3}$ show that receptor/ligand interactions mediate $\mathrm{COX}$ induction and subsequent downstream effects (26). In the present study, high molecular mass HA, the physiological ligand of the CD44 receptor, was a potent inducer of COX-2 and $\mathrm{PGI}_{2}$ production in EC. Stimulation of cells with fragments of HA did not result in stimulation of COX-2 expression. These differences between the role of native $\mathrm{HA}$ and $\mathrm{HA}$ fragments in COX-2 activation and $\mathrm{PGI}_{2}$ production correlate with their effect on VEGF production and induction of EC proliferation. In terms of signaling, this would suggest that the COX-2 induction, $\mathrm{PGI}_{2}$ formation, VEGF production and cellular proliferation induced by engagement of CD44 is dependent on a high avidity interaction that can only be achieved with high molecular mass HA and also by antibody cross-linking. However, fragments of HA have been shown to have potent signaling capacity mediated through CD44 in many cellular systems $(31,33,40)$ resulting in the activation of $\mathrm{NF \kappa B}$ and transcription of proinflammatory genes. HA degradation products or "angiogenic oligosaccharides of hyaluronan" have also been shown to stimulate EC proliferation and transient up-regulation of immediate early genes including c-fos, c-jun and jun-B. (41). It has become clear, however, that the term "HA fragment" is heterogeneic and that it covers a multitude of sizes. In the study of Deed et al. (41), only fragments ranging in size from 1.35 to $4.35 \mathrm{kDa}$ were angiogenic, while the size of our fragments were $200 \mathrm{kDa}$. HA fragments are generated at sites of inflammation and are also 
increased with carcinogenesis, which may correlate with increased hyaluronidase activity (4244). Although native HA has not been closely associated with induction of proinflammatory gene expression, it does itself have distinct signaling properties. Our results support the observations that HA and HA fragments transduce distinct signals.

Although this is the first study to demonstrate induction of COX-2 via the engagement of CD44, these two molecules display a parallel expression pattern in many physiological and pathological conditions. Expression of both CD44 and COX-2 can be induced by cytokines, growth factors, and tumor promoters (45-48), and COX-2 is a source of PG formation during inflammation, embryogenesis, and tumor growth, processes in which CD44 also plays major roles. Both CD44 and COX-2 are overexpressed in a variety of malignancies and have been linked to matrix metalloproteinase expression/activity, cell migration, invasion, and tumor metastasis $(49,50)$. Both COX-2 and CD44 (particularly variant CD44) have been implicated in the pathogenesis of colon cancer $(51,52)$. Dohadwala et al. $(53,54)$ investigated the impact of COX-2 expression in lung cancer invasiveness. They demonstrated that nonsmall cell lung cancer cells transduced with COX-2 cDNA showed enhanced invasive capacity and also over-expressed CD44.

In this study, ligation of CD44 by mAbs or its natural ligand HA induced VEGF secretion by EC. HA was a potent stimulus for VEGF production. This HA-driven VEGF secretion was completely abrogated by blocking CD44 antibodies that inhibit HA-mediated signaling. In addition, CD44-mediated COX-2 induction was significantly inhibited by a neutralizing VEGF antibody, indicating that the VEGF pathway is driving COX-2 activation. VEGF mediates its effects through two receptors, VEGFR-1 and -2. VEGFR-2 mediates much of the signaling in EC $(15,16)$, which leads to actin reorganization, membrane ruffling, and proliferation, resulting in vascular growth and angiogenesis. EC proliferation stimulated through CD44 (via mAbs and HA) was also completely inhibited by blocking CD44 mAbs that attenuate HA signaling. Importantly, this HA-stimulated EC proliferation was also blocked by a COX-2 (but not a COX1)-specific inhibitor. The effects of high molecular mass HA on EC proliferation and, ultimately, vessel formation are complex and are believed to be mediated by multiple HA receptors. Savani et al. (9) have demonstrated that CD44 is the major determinant of EC adhesion to HA and EC proliferation, whereas another HA receptor, receptor for HA-mediated motility (RHAMM), regulates EC migration through the basement membrane substrate matrigel (9). Our finding that HA-CD44-mediated signaling in EC stimulates proliferation is consistent with this.

Previous studies have observed individual roles for CD44, COX, and VEGF in processes such as embryogenesis, angiogenesis, cellular proliferation, and wound healing and in pathophysiological conditions such as cancer and inflammation. However, this is the first study to demonstrate a mechanistic link between engagement of CD44, induction of COX-2 gene expression, and production of VEGF in EC signaling. This novel pathway and its products are potentially central to all of the above processes and may be a target used in the design of therapeutic strategies to treat tumor growth, diabetic retinopathy, and inflammatory conditions such as rheumatoid arthritis. 


\section{ACKNOWLEDGMENTS}

This work was supported by The Health Research Board of Ireland and the Higher Education Authority Program for Research in Third Level Institutions. We are grateful to Tara Finn for the careful reading of this manuscript. Current address for D. Fitzgerald: Conway Institute of Biomolecular and Biomedical Research, University College Dublin, Belfield, Dublin 4, Ireland.

\section{REFERENCES}

1. Ponta, H., and Herrlich, P. (1998) The CD44 protein family: roles in embryogenesis and tumour progression. Front. Biosci. 3, 650-656

2. Avigdor, A., Goichberg, P., Shivtiel, S., Dar, A., Peled, A., Samira, S., Kollet, O., Hershkoviz, R., Alon, R., Hardan, I., et al. (2004) CD44 and hyaluronic acid cooperate with SDF-1 in the trafficking of human CD34+ stem/progenitor cells to the bone marrow. Blood 103, 2981-2989

3. Guntert, U. (1999) Importance of CD44 variant isoforms in mouse models for inflammatory bowel disease. Curr. Top. Microbiol. Immunol. 246, 307-312

4. Naor, D., Sionov, R. V., and Ish-Shalom, D. (1997) CD44: structure, function and association with the malignant process. Adv. Cancer Res. 71, 241-319

5. Lesley, J., and Hyman, R. (1998) CD44 structure and function. Front. Biosci. 3, 616-630

6. Ponta, H., Sherman, L., and Herrlich, P. (2003) CD44: from adhesion molecules to signaling regulators. Nat. Rev. Mol. Cell Biol. 4, 33-45

7. Griffioen, A. W., Coenen, M. J. H., Damen, C. A., Hellwig, S. M. M., van Weering, D. H. J., Vooys, W., Blijham, G. H., and Groenewegen, G. (1997) CD44 is involved in tumour angiogenesis; an activation antigen on human endothelial cells. Blood 90, 1150-1159

8. Ohizumi, I., Harada, N., Taniguchi, K., Tsutsumi, Y., Nakagawa, S., Kaiho, S., and Mayumi, T. (2000) association of CD44 with OTS-8 in tumour vascular endothelial cells. Biochim. Biophys. Acta 1497, 197-203

9. Savani, R. C., Cao, G., Pooler, P. M., Zaman, A., Zhou, Z., and DeLisser, H. M. (2001) Differential involvement of the hyaluronan (HA) receptors CD44 and receptor for HAmediated motility in endothelial cell function and angiogenesis. J. Biol. Chem. 276, 3677036778

10. Rahmanian, M., and Heldin, P. (2002) Testicular hyaluronidase induces tubular structures of endothelial cells grown in three-dimensional collagen gel through a CD44-mediated mechanism. Int. J. Cancer 97, 601-607

11. Gospodarowicz, D., Abraham, J. A., and Schilling, J. (1989) Isolation and characterization of a vascular endothelial cell mitogen produced by pituitary-derived folliculo stellate cells. Proc. Natl. Acad. Sci. USA 86, 7311-7315 
12. Leung, D. W., Cachianes, G., Kuang, W. J., Goeddel, D. V., and Ferrara, N. (1989) Vascular endothelial growth factor is a secreted angiogenic mitogen. Science 246, 1306-1309

13. Houck, K. A., Ferrara, N., Winer, J., Cachianes, G., Li, B., and Leung, D. W. (1991) The vascular endothelial growth factor family: identification of a fourth molecular species and characterization of alternative splicing of RNA. Mol. Endocrinol. 5, 1806-1814

14. Poltorak, Z., Cohen, T., Sivan, R., Kandelis, Y., Spira, G., Vlodavsky, I., Keshet, E., and Neufeld, G. (1997) VEGF145, a secreted vascular endothelial growth factor isoform that binds to extracellular matrix. J. Biol. Chem. 272, 7151-7158

15. Jakeman, L. B., Winer, J., Bennett, G. L., Altar, C. A. and Ferra, N. (1992) Binding sites for vascular endothelial growth factor are localised on endothelial cells in adult rat issues. $J$. Clin. Invest. 89, 244-253

16. Millauer, B., Wizigmann-Voos, S., Schnurch, H., Martinez, R., Moller, N. P. H., Risau, W., and Ullrich, A. (1993) High-affinity VEGF binding and development expression suggest Flk-1 as a major regulator of vasculogenesis and angiogenesis. Cell 72, 835-846

17. Soker, S., Takashima, S., Miao, H. Q., Neufeld, G., and Klagsbrun, M. (1998) Neuropilin-1 is expressed by endothelial and tumor cells as an isoform-specific receptor for vascular endothelial growth factor. Cell 92, 735-745

18. Wheeler-Jones, C., Abu-Ghazaleh, R., Cospedal, R., Houliston, R. A., Martin, J., and Zachary, I. (1997) Vascular endothelial growth factor stimulates prostacyclin production and activation of cytosolic phospholipase A2 in endothelial cells via p42/p44 mitogen-activated protein kinase. FEBS Lett. 420, 28-32

19. He, H., Venema, V. J., Gu, X., Venema, R. C., Marrero, M. B., and Caldwell, R. B. (1999) Vascular endothelial growth factor signals endothelial cell production of nitric oxide and prostacyclin through flk-1/KDR activation of c-Src. J. Biol. Chem. 274, 25130-25135

20. Williams, C. S., Smalley, W., and DuBois, R. N. (1997) Aspirin use and potential mechanisms for colorectal cancer prevention. J. Clin. Invest. 100, 1-5

21. Smith, C. J., Morrow, J. D., Roberts, L. J., and Marnett, L. J. (1993) Differentiation of monocytoid THP-1 cells with phorbol ester induces expression of prostaglandin endoperoxide synthase-1 (COX-1). Biochem. Biophys. Res. Commun. 192, 787-793

22. Tsujii, M., Kawano, S., Tsuji, S., Sawaoka, H., Hori, M., and DuBois, R. N. (1998) Cyclooxygenase regulates angiogenesis induced by colon cancer cells Cell 93, 705-716

23. Sirios, J., Simmons, D., and Richards, J. S. (1992) Hormonal regulation of messenger ribonucleic acid encoding a novel isoform of prostaglandin endoperoxide $\mathrm{H}$ synthase in rat preovulatory follicles. Induction in vivo and in vitro J. Biol. Chem. 267, 11586-11592 
24. Jones, D. A., Carlton, D. P., McIntyre, T. M., Zimmerman, G. A., and Prescott, S. M. (1993) Molecular cloning of human prostaglandin endoperoxide synthase type II and demonstration of expression in response to cytokines. J. Biol. Chem. 272, 31742-31748

25. Murphy, J. F., and Fitzgerald, D. J. (2001) Vascular endothelial cell growth factor (VEGF) induces cyclooxygenase (COX)-dependent proliferation of endothelial cells (EC) via the VEGF-2 receptor. FASEB J. 15, 1667-1669

26. Murphy, J. F., Steele, C., Belton, O., and Fitzgerald D. J. (2003) Induction of cyclooxygenase-1 and -2 modulates angiogenic responses to engagement of alphavbeta3. $\mathrm{Br}$. J. Haematol. 121, 157-64

27. Kelleher, D., Murphy, A., Lynch, S., and O'Farrelly, C. (1994) Adhesion molecules used in binding of intraepithelial lymphocytes to human enterocytes. Eur. J. Immunol. 24, 10131016

28. Kelleher, D., Murphy, A., Feighery, C., and Casey, E.B. (1995) Leukocyte functionassociated antigen 1 (LFA-1) and CD44 are signaling molecules for cytoskeleton-dependent morphological changes in activated T cells. J. Leukoc. Biol. 58, 539-546

29. Anstee, D. J., Gardner, B., Spring, F. A., Holmes, C. H., Simpson, K. L., Parsons, S. F., mallinson, G., Yousaf, S. M. and Judson, P. A. (1991) New monoclonal antibodies in CD44 and CD58: their use to quantify CD44 and CD58 on normal erythrocytes and to compare the distribution of CD44 and CD58 in human tissues. Immunology 74, 197-205

30. Jaffe, E. A., Nachman, R. L., Becker, C. G., and Minick, C. R. (1973) Culture of human endothelial cells derived from umbilical veins. Identification by morphologic and immunologic criteria. J. Clin. Invest. 52, 2745-2756

31. Fitzgerald, K. A., Bowie, A. G., Skeffington, B. S., and O'Neill, L. A. (2000) Ras, protein kinase $\mathrm{C}$ zeta, and I kappa B kinases 1 and 2 are downstream effectors of CD44 during the activation of NF-kappa B by hyaluronic acid fragments in T-24 carcinoma cells. J. Immunol. 164, 2053-2063

32. Katoh, S., Matsumoto, N., Kawakita, K., Tominaga, A., Kinkade, P. W., and Matsukura, S. (2003) A role for CD44 in an antigen-induced murine model of pulmonary eosinophilia. $J$. Clin. Invest. 111, 1563-1570

33. McKee, C. M., Penno, M. B., Cowman, M., Burdick, M. D., Strieter, R. M., Bao, C., and Noble, P. W. (1996) Hyaluronan (HA) fragments induce chemokine gene expression in alveolar macrophages. The role of HA size and CD44. J. Clin. Invest. 98, 2403-2413

34. Prescott, S. (2000) Is cyclooxygenase-2 the alpha and the omega in cancer? J. Clin. Invest. 105, 1511-1513

35. Masferrer, J. L., Leahy, K. M., Koki, A. T., Zweifel, B. S., Settle, S. L., Woerner, B. M., Edwards, D. A., Flickinger, A. G., Moore, R. J., and Seibert, K. (2000) Anti-angiogenic and anti-tumour activities of cyclooxygenase-2 inhibitors. Cancer Res. 60, 1306-1311 
36. Tarnawski, A. S., and Jones, M. K. (2003) Inhibition of angiogenesis by NSAIDs: molecular mechanisms and clinical implications. J. Mol. Med. 81, 627-636

37. Friedl, P., and Brocker, E. B. (2000) T-cell migration in three-dimensional extracellular matrix: guidance by polarity and sensations. Dev. Immunol. 7, 249-266

38. Foger, N., Marhaba, R., and Zoller, M. (2000) CD44 supports T cell proliferation and apoptosis by apposition of protein kinases. Eur. J. Immunol. 30, 2888-2899

39. Hodge-Dufour, J., Noble, P. W., Horton, M. R., Bao, C., Wysoka, M., Burdick, M. D., Strieter, R. M., Trinchieri, G., and Pure, E. (1997) Induction of IL-12 and chemokines by hyaluronan requires adhesion-dependent priming of resident but not elicited macrophages. $J$. Immunol. 159, 2492-2500

40. McKee, C. M., Lowenstein, C. J., Horton, M. R., Wu, J., Bao, C., Chin, B. Y., Choi, A. M., and Noble, P. W. (1997) Hyaluronan fragments induce nitric-oxide synthase in murine macrophages through a nuclear factor kappaB-dependent mechanism. J. Biol. Chem. 272, 8013-8018

41. Deed, R., Rooney, P., Kumar, P., Norton, J. D., Smith, J., Freemont, A. J., and Kumar, S. (1997) Early-response gene signalling is induced by angiogenic oligosaccharides of hyaluronan in endothelial cells. Inhibition by non-angiogenic, high-molecular-weight hyaluronan. Int. J. Cancer 71, 251-256

42. Teder, P., Vandivier, R. W., Jiang, D., Liang, J., Cohn, L., Pure, E., Henson, P. M., and Noble, P. W. (2002) Resolution of lung inflammation by CD44. Science 296, 155-158

43. Horton, M. R., Shapiro, S., Bao, C., Lowenstein, C. J., and Noble, P. W. (1999) Induction and regulation of macrophage metalloelastase by hyaluronan fragments in mouse macrophages. J. Immunol. 162, 4171-4176

44. Lokeshwar, V. B., Obek, C., Pham, H. T., Wei, D., Young, M. J., Duncan, R. C., Soloway, M. S., and Block, N. L. (2000) Urinary hyaluronic acid and hyaluronidase: markers for bladder cancer detection and evaluation of grade. J. Urol. 163, 348-356

45. Diaz, F., and Bourguignon, L. Y. (2000) Selective down-regulation of IP(3)receptor subtypes by caspases and calpain during TNF alpha -induced apoptosis of human Tlymphoma cells. Cell Calcium 27, 315-328

46. Uracz, W., Uracz, D., Olszanecki, R., and Gryglewski, R. J. (2002) Interleukin-1beta induces functional prostaglandin $\mathrm{E}$ synthase in cultured human umbilical vein endothelial cells. J. Physiol. Pharmacol. 53, 643-654

47. Gee, K., Lim, W., Ma, W., Nandan, D., Diaz-Mitoma, F., Kozlowski, M., and Kumar, A. (2002) Differential regulation of CD44 expression by lipopolysaccharide (LPS) and TNFalpha in human monocytic cells: distinct involvement of c-Jun N-terminal kinase in LPSinduced CD44 expression. J. Immunol. 169, 5660-5672 
48. Fitzgerald, K. A., and O'Neill, L. A. (1999) Characterization of CD44 induction by IL-1: a critical role for Egr-1. J. Immunol. 162, 4920-4927

49. Trejdosiewicz, L. K., Morton, R., Yang, Y., Banks, R. E., Selby, P. J., and Southgate, J. (1998) Interleukins 4 and 13 upregulate expression of CD44 in human colonic epithelial cell lines. Cytokine 10, 756-765

50. Kim, H. S., Youm, H. R., Lee, J. S., Min, K. W., Chung, J. H., and Park, C. S. (2003) Correlation between cyclooxygenase-2 and tumor angiogenesis in non-small cell lung cancer. Lung Cancer 42, 163-170

51. Yamada, Y., Itano, N., Narimatsu, H., Kudo, T., Hirohashi, S., Ochiai, A., Tohnai, I., Ueda, M., and Kimata, K. (2003) CD44 variant exon 6 expressions in colon cancer assessed by quantitative analysis using real time reverse transcriptase-polymerase chain reaction. Oncol. Rep. 10, 1919-1924

52. Oshima, M., Murai, N., Kargman, S., Arguello, M., Luk, P., Kwong, E., Taketo, M. M., and Evans, J. F. (2001) Chemoprevention of intestinal polyposis in the Apcdelta716 mouse by rofecoxib, a specific cyclooxygenase-2 inhibitor. Cancer Res. 61, 1733-1740

53. Dohadwala, M., Luo, J., Zhu, L., Lin, Y., Dougherty, G. J., Sharma, S., Huang, M., Pold, M., Batra, R. K., and Dubinett, S. M. (2001) Non-small cell lung cancer cyclooxygenase-2dependent invasion is mediated by CD44. J. Biol. Chem. 276, 20809-20812

54. Dohadwala, M., Batra, R. K., Luo, J., Lin, Y., Krysan, K., Pold, M., Sharma, S., and Dubinett, S. M. (2002) Autocrine/paracrine prostaglandin E2 production by non-small cell lung cancer cells regulates matrix metalloproteinase-2 and CD44 in cyclooxygenase-2dependent invasion. J. Biol. Chem. 277, 50828-50833

Received March 7, 2004; accepted November 15, 2004. 
Fig. 1
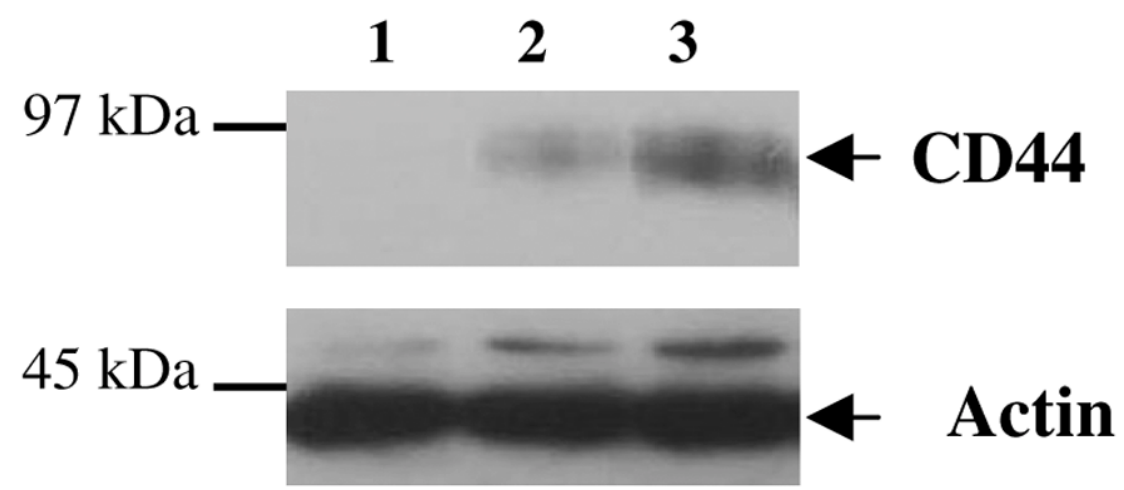

Figure 1. HUVEC express CD44. HUVEC (passage 2) were seeded onto $0.2 \%$ gelatin-coated T75 flasks at cell density of $1.5 \times 10^{5}$ per flask in M199 complete medium. They were then lysed 24 (lane 1), 48 (lane 2), and 72 (lane 3) h later and analyzed for CD44 and actin (loading control) expression by Western blot analysis. Anti-CD44 was Bric-238, and Antiactin (polyclonal) was from Sigma. 
Fig. 2

A
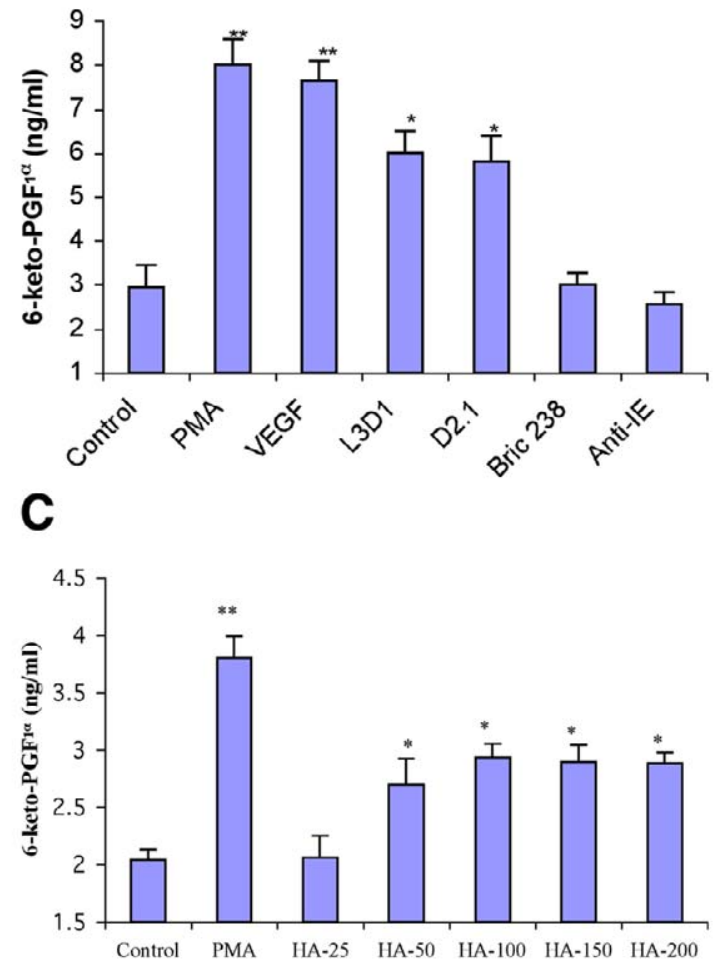

E

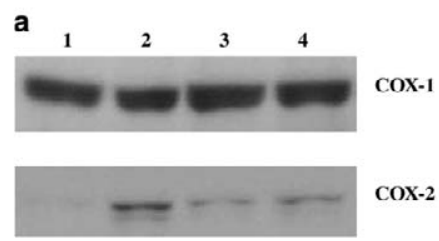

b

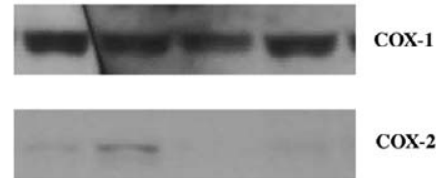

B
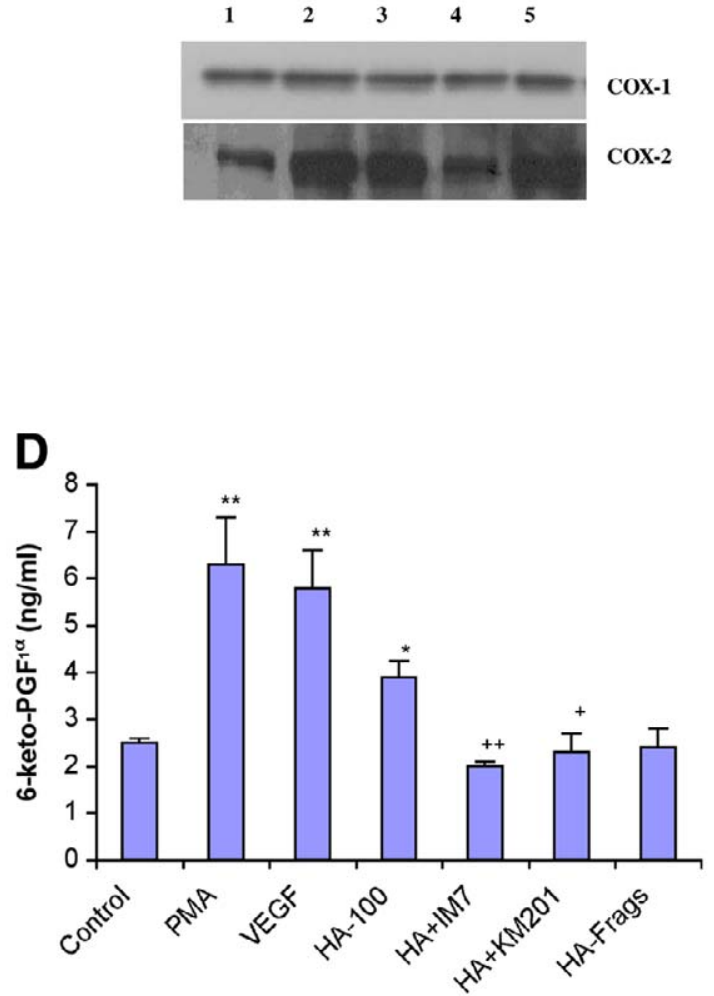

Figure 2. Anti-CD44 mAbs and high molecular weight HA induce COX-2. EC were plated onto 6- or 24-well plates and serum-starved overnight in M199/2.5\% FBS. Aspirin $(200 \mu \mathrm{M})$ was added for 45 min, washed, and then treated with mAbs, HA, HA fragments, or control agonist for a period of 3-4 h. Arachidonic acid was used as substrate to measure enzyme activity. COX protein expression was measured by Western blot analysis as described in Materials and Methods. Data are means \pm SE from 5-6 independent experiments. A) 6-keto-PGF 1 $_{\alpha}$ generation after ligation of EC with stimulating CD44 antibodies (L3D1 and D2.1). PMA and VEGF were used as positive controls with the nonstimulating IgM antiCD44 Bric 238 and an isotype Ig (Anti-IE) as negative controls. B) COX-1 and COX-2 protein induction by anti-CD44 mAbs as detected by Western blot analysis. Lane 1, control; lane 2, PMA; lane 3, D2.1; lane 4, Bric 238 (nonstimulating anti CD44); lane 5 L3D1. C) HA induces 6-keto-PGF ${ }_{1 \alpha}$ in a concentration-dependent manner. Cells were incubated with $\mathrm{HA}$ at concentrations ranging from 25 to $200 \mu \mathrm{g} / \mathrm{ml}$. D) 6-keto-PGF ${ }_{1 \alpha}$ induction by HA is inhibited by blocking mAbs to CD44(IM7 or KM201). Blocking Abs were added 30 min before addition of HA. E) a) HA induces COX-2 but not COX1 in EC. Lane 1, resting cells; lane 2, PMA $(1 \mu \mathrm{M})$; lanes 3 and 4, cells incubated with high molecular weight HA (100 $\mu \mathrm{g} / \mathrm{ml}$ ) for 3 and $6 \mathrm{~h}$, respectively. $\boldsymbol{b}$ ) HA fragments induce neither COX-1 nor COX-2 in EC. Lane 1, resting cells; lane 2, PMA $(1 \mu \mathrm{M})$; lanes 3 and 4, cells incubated with HA fragments $(100 \mu \mathrm{g} / \mathrm{ml})$ for 3 and $6 \mathrm{~h}$, respectively. Data are means \pm SE from 3-4 independent experiments. ${ }^{*} P<0.05 ;{ }^{*} P<0.01$; HA vs. HA and $\mathrm{mAbs}{ }^{++} P<0.01 ;{ }^{+} P<0.05$. 
Fig. 3

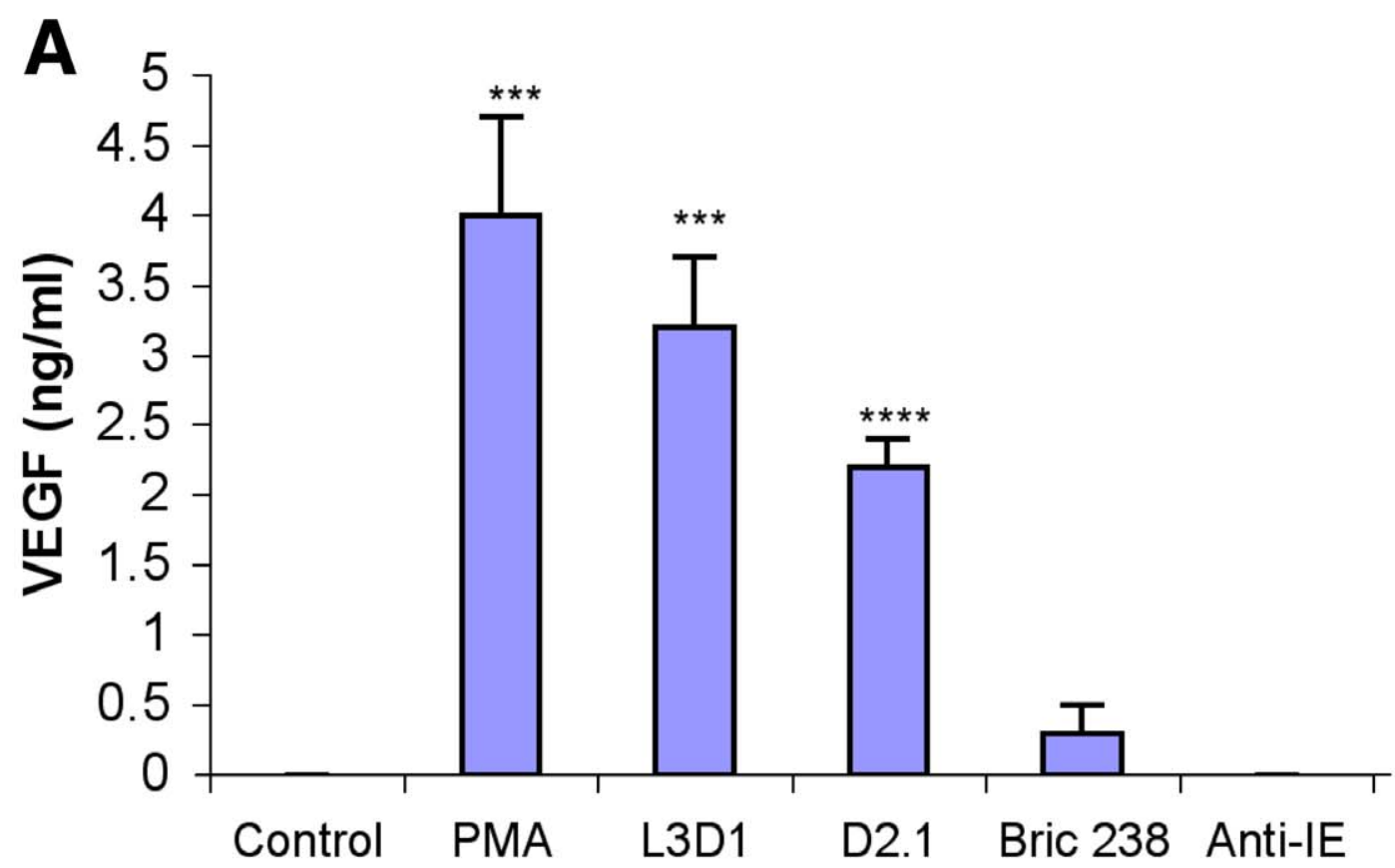

B

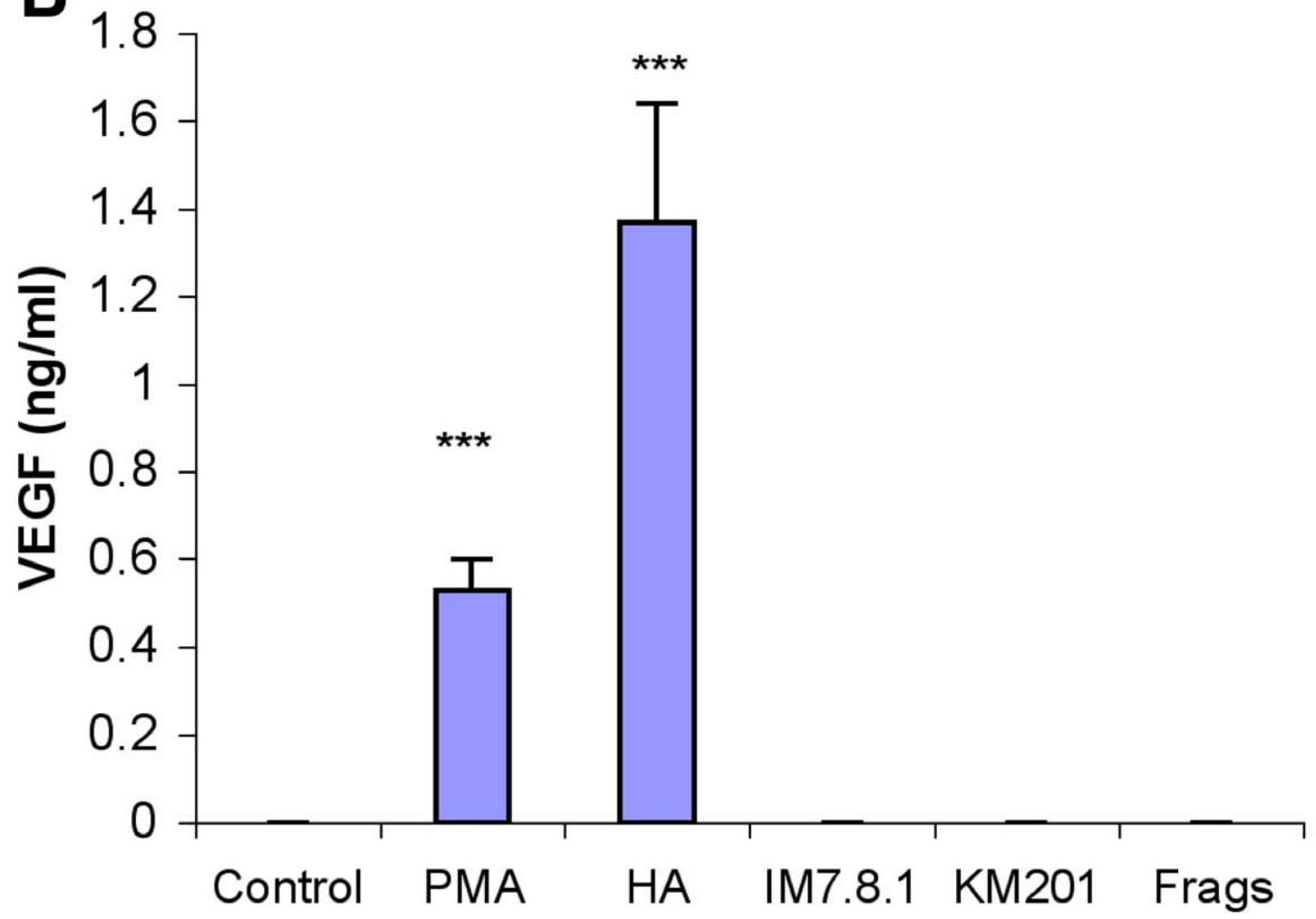

Figure 3. Effect of CD44 mAbs and HA on VEGF production. EC were plated onto 6- or 24-well plates and serumstarved overnight in M199/2.5\% FBS. Aspirin $(200 \mu \mathrm{M})$ was added for 45 min, washed, and then treated with mAbs, HA, HA fragments (Frags), or control agonist for a period of 3-4 h. At the end of the incubation period, supernatant samples were removed and assayed for VEGF by ELISA. A) Stimulation of VEGF production after ligation of EC with stimulating CD44 antibodies (L3D1 and D2.1). PMA was used as a positive control with the nonstimulating IgM anti-CD44, Bric 238, and an isotype Ig (Anti-IE) as negative controls. B) HA induces VEGF production that is inhibited by blocking mAbs. Blocking mAbs (IM7 or KM201) were added 30 min before addition of HA. Data are means \pm SE from 3 independent experiments. $* * * P<0.005$; $* * * * P<0.001$. 
Fig. 4
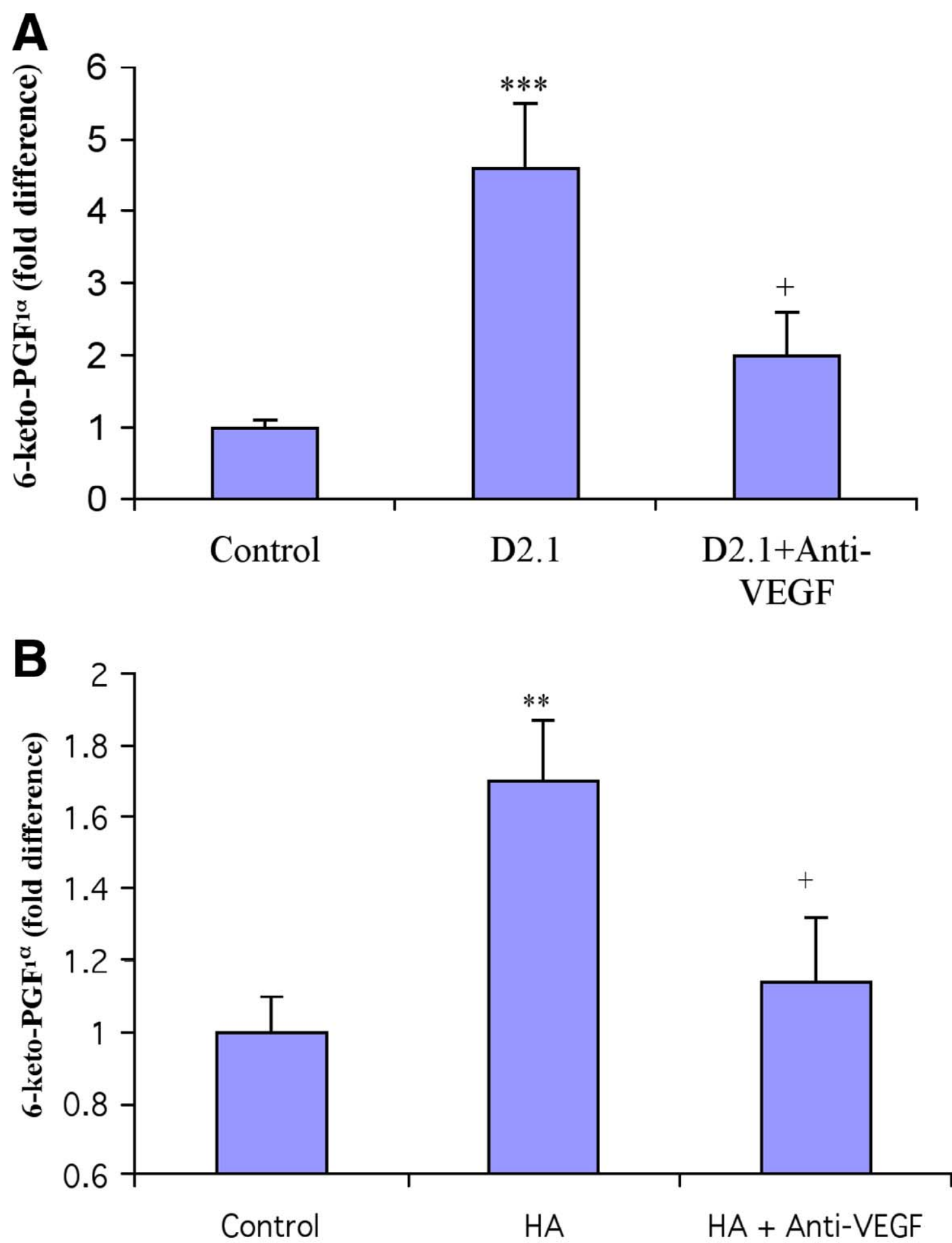

Figure 4. A neutralising antbody to VEGF inhibits Anti-CD44 mAb and high molecular weight HA induction of COX-2. EC were plated onto 6- or 24-well plates and serum-starved overnight in M199/2.5\% FBS. Aspirin (200 $\mu$ M) was added for $45 \mathrm{~min}$, washed, and then treated with CD44mAb or HA for a period of 3-4 h. Neutralizing anti-VEGF was added $30 \mathrm{~min}$ before addition of anti-CD44 antibody or HA. Arachidonic acid was used as substrate to measure enzyme activity. $\boldsymbol{A})$ 6-keto-PGF ${ }_{1 \alpha}$ generation after ligation of EC with stimulating CD44 antibody (D2.1) in the presence and absence of neutralizing anti-VEGF. B) 6-keto-PGF ${ }_{1 \alpha}$ generation after ligation of EC with HA in the presence and absence of neutralizing anti-VEGF $m A b$. Data are means \pm SE from 3 independent experiments. ${ }^{* * *} P<0.005$, ${ }^{*} * P<0.01,{ }^{+} P$ $<0.05$. 
Fig. 5
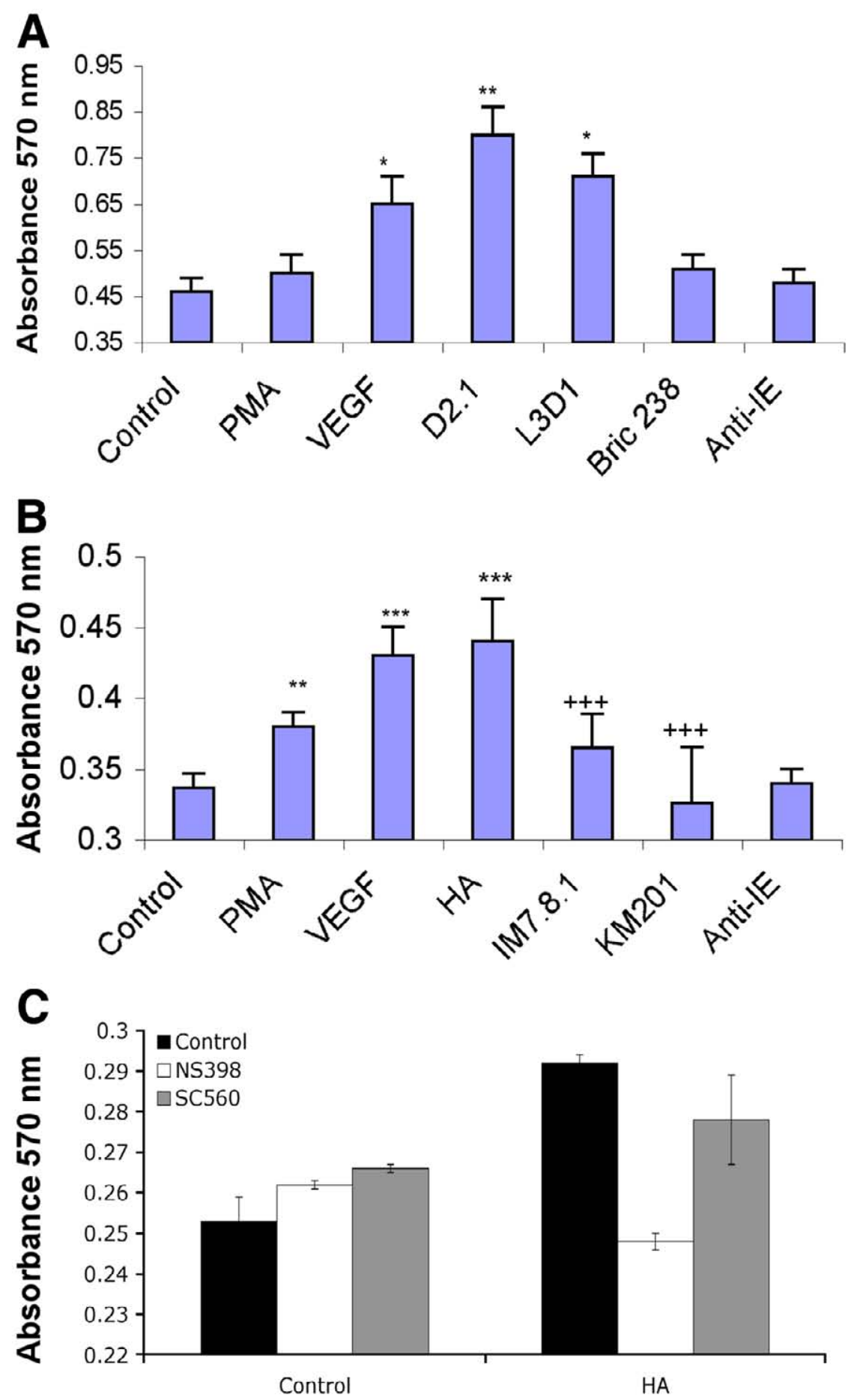

Figure 5. Effect of mAbs and HA on cell proliferation. EC were grown to 50-60\% confluency in 96-well tissue culture plates, serum-starved (2.5\% FBS) overnight, and then treated with aspirin for 45 min. MAbs, HA or HA fragments, in the presence or absence of blocking mAbs, were then added for 8-9 h. 3-[4, 5-dimethylthiazol-2-y]-2, 5-diphenyltetrazolium bromide (MTT) was then added for a further $1 \mathrm{~h}$, cells were lysed in detergent, and absorbance was read at $570 \mathrm{~nm}$. A) EC proliferation after ligation of cells with stimulating CD44 antibodies (L3D1 and D2.1). PMA and VEGF were used as positive controls with the nonstimulating IgM anti-CD44, Bric 238, and an isotype Ig (Anti-IE) as negative controls. B) HA induces EC proliferation that is inhibited by blocking mAbs. Blocking mAbs (IM7 or KM201) were added 30 min before addition of HA. C) HA-stimulated EC proliferation is attenuated by the COX-2-selective inhibitor NS398. COX-1 (SC 560, $1 \mu \mathrm{M}$ ) and COX-2 (NS398, $1 \mu \mathrm{M}$ )-specific inhibitors were used, inhibitors were added 30 min before addition of HA. Data are means \pm SE from 3-5 independent experiments. ${ }^{*} \mathrm{P}<0.05 ; * * * P<0.005$; ${ }^{*} * * * P<0.001 ;{ }^{+++} P<0.005$; ${ }^{++++} P<0.001$. 